\title{
Developing Superplasticity in Ultrafine-Grained Metals
}

\author{
M. KAWASAKI ${ }^{a, b}$ AND T.G. LANGDON ${ }^{b, c, *}$
}

${ }^{a}$ Division of Materials Science and Engineering, Hanyang University, Seoul 133-791, South Korea

${ }^{b}$ Departments of Aerospace and Mechanical Engineering and Materials Science, University of Southern California,

Los Angeles, CA 90089-1453, USA

${ }^{c}$ Materials Research Group, Faculty of Engineering and the Environment, University of Southampton, Southampton SO17 1BJ, UK

\begin{abstract}
The processing of bulk metals through the application of severe plastic deformation provides an opportunity for achieving exceptional grain refinement with grain sizes typically lying in the submicrometer or even the nanometer range. Provided these small grains are reasonably stable at elevated temperatures, these ultrafine-grained metals will exhibit excellent superplastic properties when pulled in tension at elevated temperatures. Most ultrafinegrained materials have been produced using either equal-channel angular pressing or high-pressure torsion. This paper examines the results for superplasticity reported to date using metallic alloys processed by equal-channel angular pressing and high-pressure torsion, compares the experimental strain rates with those predicted using the theoretical model for conventional superplastic flow and then demonstrates the feasibility of preparing deformation mechanism maps that provide comprehensive information on the flow mechanisms.
\end{abstract}

DOI: 10.12693 /APhysPolA.128.470

PACS: 81.05.Bx, 81.20.Hy, 81.40.Lm

\section{Introduction}

When a metal specimen is pulled in tension, it invariably develops a neck within the gauge length and ultimately breaks at a relatively low elongation to failure. However, under some testing conditions it is possible for the material to pull out to exceptionally high neck-free elongations in the process known as superplasticity. The potential for achieving very high tensile elongations was first reported eighty years ago in the classic experiments conducted by Pearson [1] on the $\mathrm{Bi}-\mathrm{Sn}$ and $\mathrm{Pb}-\mathrm{Sn}$ eutectic alloys. In these very early experiments, a remarkable elongation of $1950 \%$ was achieved in the $\mathrm{Bi}-\mathrm{Sn}$ eutectic alloy. Many later experiments, conducted at laboratories around the world, produced even higher elongations including a record-breaking $7550 \%$ in the $\mathrm{Pb}$ $62 \%$ Sn eutectic alloy [2]. These extensive experiments on the processing and properties of superplastic alloys led ultimately to the development of the commercial superplastic forming industry in which sheet metals are formed superplastically into the complex and curved shapes that are needed in many applications ranging from aerospace to automotive and architectural [3].

The objective of this report is to summarize the basic principles of superplasticity in the following section and then, in the subsequent sections, to examine the significance of superplastic flow in ultrafine-grained (UFG) materials where the grain sizes are typically within the submicrometer range.

\section{The characteristics of superplasticity}

It is now well established that the occurrence of superplastic flow has two fundamental requirements [4]. First,

\footnotetext{
*corresponding author; e-mail: langdon@soton.ac.uk
}

the grain size of the material must be very small and typically less than approximately $10 \mu \mathrm{m}$. Second, since superplastic flow is a diffusion-controlled process, it requires testing at a high temperature, typically greater than about $0.5 T_{\mathrm{m}}$ where $T_{\mathrm{m}}$ is the absolute melting temperature, so that the diffusion process is reasonably rapid.

The steady-state strain rate, $\dot{\varepsilon}$, occurring during the flow of metals at elevated temperatures may be expressed by a simple relationship of the form [4-6]:

$$
\dot{\varepsilon}=\frac{A D G \boldsymbol{b}}{k T}\left(\frac{\boldsymbol{b}}{d}\right)^{p}\left(\frac{\boldsymbol{\sigma}}{G}\right)^{n},
$$

where $A$ is a dimensionless constant, $D$ is the appropriate diffusion constant $\left[=D_{0} \exp (-Q / R T)\right.$ where $D_{0}$ is a frequency factor, $Q$ is the activation energy, $R$ is the gas constant and $T$ is the absolute temperature], $G$ is the shear modulus, $\boldsymbol{b}$ is the Burgers vector, $k$ is the Boltzmann constant, $d$ is the grain size, $\sigma$ is the applied stress and $n$ and $p$ are the exponents of the stress and the inverse grain size, respectively.

In practice, it was established many years ago that the measured elongation to failure is directly proportional to the strain rate sensitivity, $m$, where $m$ is the reciprocal of the stress exponent $n$ in Eq. (1) [7,8]. This means in practice that it is not easy to specifically identify materials where the flow process is true superplasticity. For example, flow controlled by the viscous glide of dislocations, as in solid solution alloys where solute atmospheres may be dragged by moving dislocations, will exhibit a stress exponent of $n=3$, equivalent to $m \approx 0.3$, so that the elongations to failure may be in excess of $100 \%$ [9]. Nevertheless, these high elongations do not represent true superplasticity.

To provide a direct definition of superplasticity, it is necessary to determine the flow mechanism and then to develop an appropriate model to describe the 
deformation behavior. It is now well established that the flow process in superplasticity is grain boundary sliding (GBS) in which the individual grains within the polycrystalline matrix move over each other in response to the applied stress [10]. This leads, ultimately, to a high elongation but with the grains remaining essentially equiaxed even after very high tensile elongations [11]. Since GBS cannot occur in isolation without opening up holes or cavities in the material, it is necessary to consider the mechanism that accommodates the sliding process. In principle, the two possible accommodation mechanisms are diffusion creep and the movement of dislocations within the grains. However, diffusion creep can be discounted because there is no elongation of the individual grains and, in addition, direct measurements of precipitate-free zones in superplastic alloys containing dispersions of particles show directly that diffusion creep is of negligible importance [12]. The alternative possibility, of accommodation through the intragranular movement of dislocations, is now well supported by several sets of careful experiments. Thus, it was shown using a copper alloy that matrix dislocations accumulate within the grains in coherent twin boundaries during superplastic flow [13], there are direct measurements of these intragranular strains in a superplastic $\mathrm{Pb}-\mathrm{Sn}$ alloy at elongations up to a total of $800 \%$ [14] and the movement of intragranular dislocations was also demonstrated using a $\mathrm{Zn}-\mathrm{Al}$ alloy containing a nanometer-scale dispersion of particles [15].

(a)

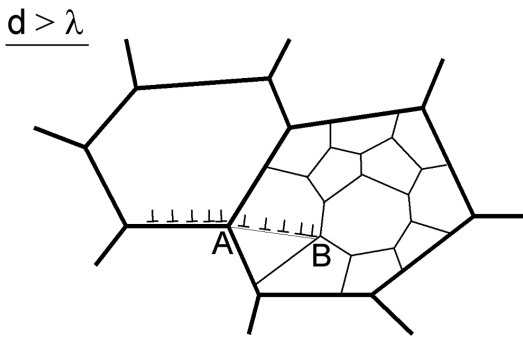

(b) $d<\lambda$

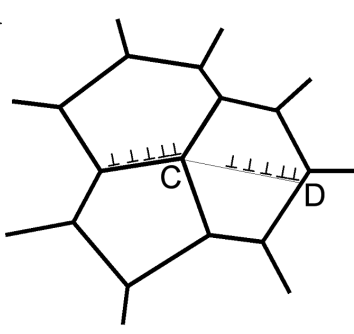

Fig. 1. A unified model for GBS under (a) conventional creep conditions where $d>\lambda$ and (b) superplastic conditions where $d<\lambda[16]$.

Based on this information, a model for superplasticity can be developed using the schematic information contained in Fig. 1 [16]. During conventional high temperature creep, the grains become divided into subgrains and numerous experiments have shown that the average size of these subgrains, $\lambda$, is inversely proportional to the applied stress through a relationship of the form [17]:

$$
\frac{\lambda}{\boldsymbol{b}}=\varsigma\left(\frac{\sigma}{G}\right)^{-1},
$$

where $\zeta$ is a constant having a value of $\approx 20$. A similar relationship applies equally to polycrystalline ceramics [18]. Thus, in Fig. 1a the situation is shown for large grains where $d>\lambda$ and the grains contain subgrains. Grain boundary sliding then produces a stress concentration at the triple point labeled $\mathrm{A}$ and this is accommodated by intragranular slip within the next grain so that dislocations pile up and then climb into the subgrain boundary at B. In Fig. 1b the situation is depicted for very small grains where $d<\lambda$, no subgrains are formed because the grains are too small, and the accommodating dislocations emanating from the triple point at $\mathrm{C}$ then climb into the opposite grain boundary at D. An early analysis showed that superplasticity requires a grain size that is smaller than the equilibrium subgrain size [19] and therefore Fig. 1a corresponds to conventional GBS in the creep of materials with large grain sizes whereas Fig. 1b corresponds to the flow of superplastic materials where no subgrains are formed within the grains.

Modeling the flow process in Fig. 1b, where GBS is accommodated by intragranular slip and subgrains are not formed, it can be shown that this process leads directly to Eq. (1) with $n \approx 2, p \approx 2, A \approx 10$ and $D=D_{\text {gb }}$ where $D_{\mathrm{gb}}$ is the coefficient for grain boundary diffusion [20]. It is important to note that the predicted superplastic strain rate varies inversely with the grain size raised to a power of 2 and this means that a reduction in grain size will lead to the occurrence of superplasticity at faster strain rates.

A stress exponent of $n \approx 2$ is consistent with the occurrence of high superplastic elongations because of the proportionality between the elongations to failure and the strain rate sensitivity, $m$. For superplasticity, a value of $n=2$ means that $m=0.5$ and this is higher than the value of $m \approx 0.3$ which applies when flow occurs through viscous glide. Therefore, high elongations are expected under true superplastic conditions. Accordingly, and in order to provide a more formal definition, it was proposed that superplasticity requires a tensile elongation of at least $400 \%$ and a measured strain rate sensitivity close to $\approx 0.5[16]$.

Since metals are generally tested under conditions where the imposed strain rate is reasonably constant, the experimental data are generally plotted in a doublelogarithmic form as the flow stress versus the imposed strain rate. Early data of this type showed that the strain rate sensitivity in the superplastic region was close to $\approx 0.5$ but there was disagreement about the situation at low stresses where there were conflicting reports of either a high strain rate sensitivity close to $\approx 1$ at the lowest stresses $[21,22]$ or a lower strain rate sensitivity of $m<0.5$ at these stresses [23-25]. Careful experiments showed that superplastic alloys exhibit three distinct regions of flow, as illustrated by the results in Fig. 2 for a $\mathrm{Zn}-22 \% \mathrm{Al}$ eutectoid alloy [26]. These results show the elongations to failure (upper) and the flow stresses 


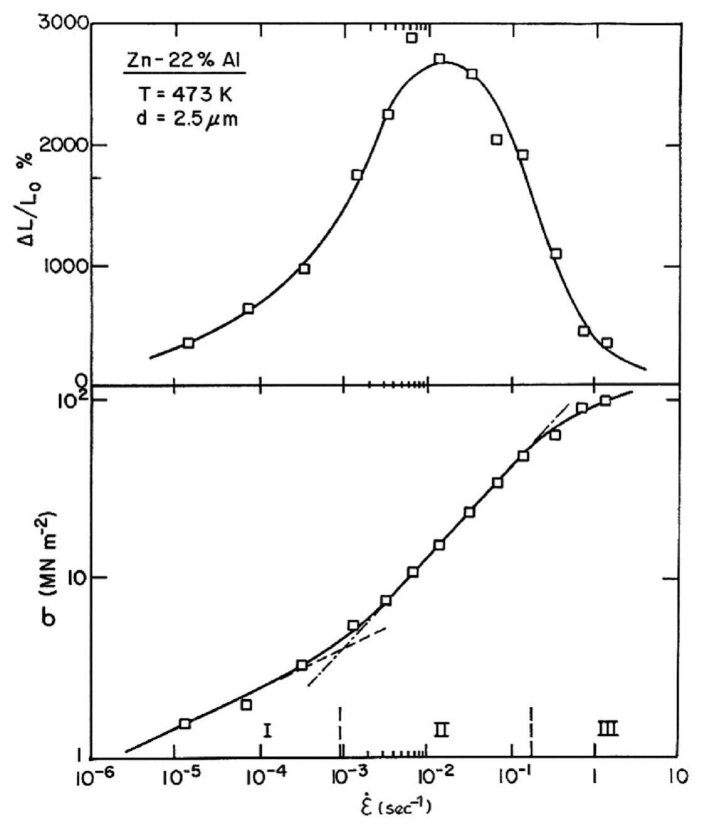

Fig. 2. Elongation to failure (upper) and flow stresses (lower) plotted as a function of the imposed strain rate for a $\mathrm{Zn}-22 \% \mathrm{Al}$ alloy having a grain size of $2.5 \mu \mathrm{m}$ tested at a temperature of $473 \mathrm{~K}[26]$.

(lower) plotted as a function of the imposed strain rate for an alloy having a grain size of $2.5 \mu \mathrm{m}$ tested at a temperature of $473 \mathrm{~K}$. Thus, the data divide into three distinct regions of flow where region II at intermediate strain rates is the true superplastic region with elongations to failure of up to $>2000 \%$, region III at high strain rates is due to the transition to a conventional dislocation mechanism such as dislocation climb and region I at low stresses is now known to arise from the segregation of impurity atoms at the grain boundaries and the interaction between these impurities and the dislocations that move along the boundaries during GBS [27-29].

\section{The significance of superplasticity for ultrafine-grained metals}

Processing through the application of severe plastic deformation (SPD) provides the opportunity for producing fully-dense polycrystalline materials where the grain sizes are often in the submicrometer or the nanometer range. Several SPD processing procedures are now available but the most important methods are equalchannel angular pressing (ECAP) and high-pressure torsion (HPT) [30]. Processing by ECAP involves pressing a rod or bar through a die where it is constrained within a channel that is bent through an abrupt angle [31] and processing by HPT involves simultaneously applying a high pressure and torsional straining to a thin disk [32]. Generally, the experimental evidence shows that processing by HPT is preferable to ECAP because it produces both smaller grains $[33,34]$ and a higher fraction of grain boundaries having high angles of misorientation [35].

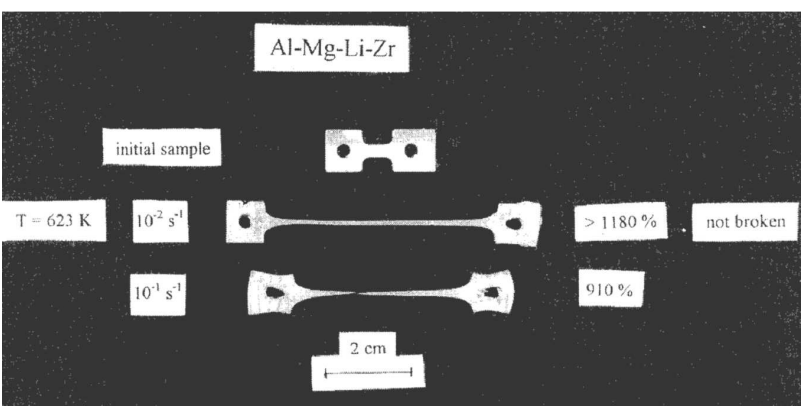

Fig. 3. A first demonstration of the occurrence of high strain rate superplasticity in a commercial $\mathrm{Al}-\mathrm{Mg}-\mathrm{Li}-\mathrm{Zr}$ alloy after processing by ECAP [39].

The potential for achieving superplasticity in metallic alloys processed by SPD was demonstrated in very early experiments conducted to examine the mechanical properties of materials after processing by HPT [36]. Subsequently, it was recognized that the inverse dependence on grain size raised to a power of $p=2$ in Eq. (1) should provide the opportunity for achieving superplastic elongations in the regime of high strain rate superplasticity [37] which is defined formally as the occurrence of superplastic elongations at strain rates at and above $10^{-2} \mathrm{~s}^{-1}[38]$. This was later achieved using two commercial aluminum alloys and an example is shown in Fig. 3 for an $\mathrm{Al}-\mathrm{Mg}-\mathrm{Li}-\mathrm{Zr}$ alloy where testing at $623 \mathrm{~K}$ gave an elongation of $1180 \%$ without breaking when testing at a strain rate of $10^{-2} \mathrm{~s}^{-1}$ [39]. Inspection shows that the sample pulling out to $>1180 \%$ in Fig. 3 exhibits no necking within the gauge length and this is consistent with the expectations for true superplasticity [40]. To date, there are numerous reports of superplastic elongations in materials processed using SPD procedures and reviews and tabulations of the experimental data are now available for alloys processed by ECAP [41] and HPT [42].

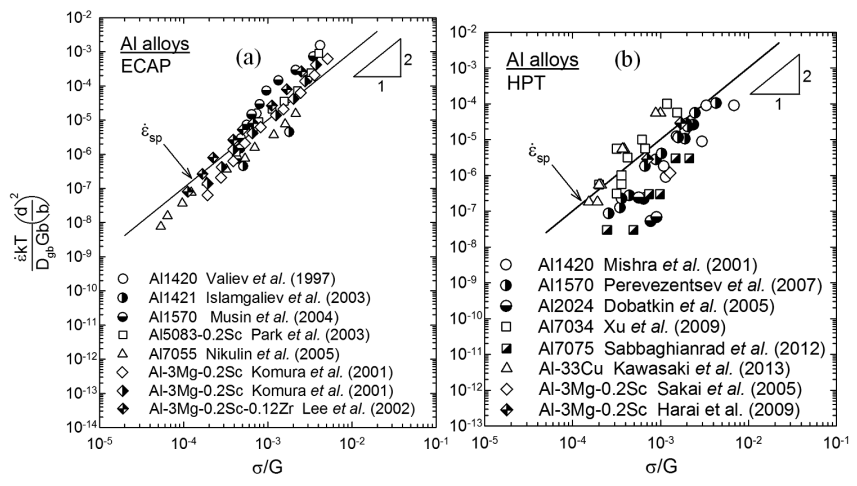

Fig. 4. Temperature and grain size compensated strain rate versus the normalized stress for various $\mathrm{Al}$ alloys processed by (a) ECAP [43] and (b) HPT [42] exhibiting superplastic behavior where experimental details are given in [39, 44-50] for ECAP and [51-58] for HPT: the solid lines show the theoretical prediction for superplastic flow in conventional metals without SPD processing. 
An important question concerns whether the rate equation for superplastic flow in materials processed by SPD is the same as the equation used for conventional superplastic materials where the grain sizes tend to be larger. Since more experimental data are available for superplastic aluminum-based alloys, it is appropriate to examine the rate equations associated with flow in these UFG materials. This approach was first adopted using published data for Al alloys processed by ECAP [43] and subsequently a similar approach was used to examine samples processed by HPT [42]. The results are given in Fig. 4 for (a) ECAP and (b) HPT: the experimental datum points shown in Fig. 4 are taken from a wide range of reports for ECAP [39, 44-50] and HPT [51-58], respectively. The results are plotted in the form of the temperature and grain size compensated strain rate versus the normalized stress so that all points should fall on or about the same line. Also shown in Fig. 4 is the predicted theoretical strain rate for superplasticity, $\dot{\varepsilon}_{\mathrm{sp}}$, based on the model derived from Fig. 1(b). It is readily apparent that the theoretical line with a slope of $n=2$ is in excellent agreement with the experimental points, thereby confirming that superplastic flow in UFG materials occurs by the same fundamental mechanism as in conventional superplastic alloys.

\section{Superplasticity in the $\mathrm{Zn}-\mathrm{Al}$ eutectoid alloy after processing by SPD}

The $\mathrm{Zn}-22 \% \mathrm{Al}$ eutectoid alloy is a classic superplastic material that was investigated extensively without processing using SPD techniques [23, 26, 59-63]. More recently, there have been several investigations of superplastic behavior in this alloy after processing by ECAP [64-67] or HPT [68].

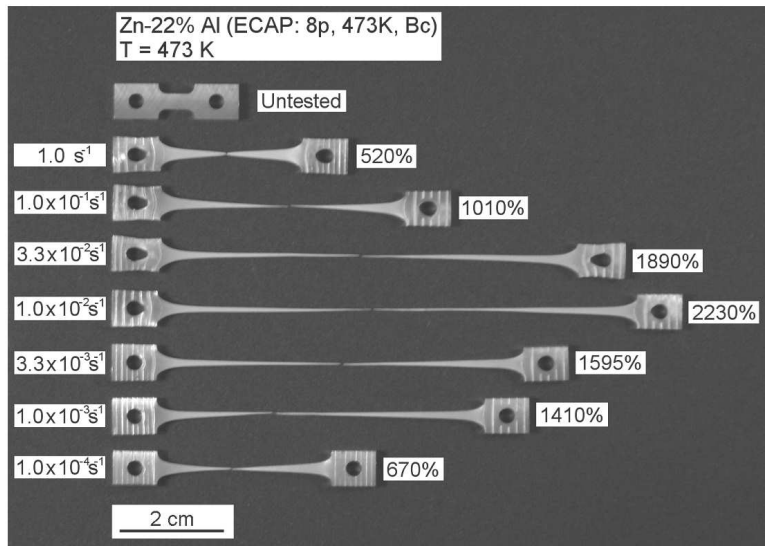

Fig. 5. The appearance of $\mathrm{Zn}-22 \% \mathrm{Al}$ specimens processed by ECAP for 8 passes at $473 \mathrm{~K}$ and pulled to failure at different strain rates at $473 \mathrm{~K} \mathrm{[64]}$.

Figure 5 shows an example of the excellent superplastic elongations that may be achieved in this alloy after processing by ECAP [64]. The alloy was pressed through 8 passes by ECAP at a temperature of $473 \mathrm{~K}$ using processing route $B_{\mathrm{C}}$ in which the specimen is rotated about the longitudinal axis by $90^{\circ}$ in the same sense between each pass [69]. The ECAP die had an internal channel angle of $90^{\circ}$ so that each pass imposed a strain of $\approx 1$ [70] and immediately prior to the tensile testing the grain size was measured as $\approx 0.9 \mu \mathrm{m}$. It is apparent that the $\mathrm{Zn}-$ $\mathrm{Al}$ alloy exhibits exceptional superplasticity when pulled to failure at $473 \mathrm{~K}$ with elongations up to $2230 \%$ at a strain rate of $1.0 \times 10^{-2} \mathrm{~s}^{-1}$. The result in Fig. 6 shows the same alloy after processing by HPT through 5 turns at room temperature using a pressure of $6.0 \mathrm{GPa}$ and a rotational speed of $1 \mathrm{rpm}$ [68]. Again the samples were pulled to failure at $473 \mathrm{~K}$ and the maximum recorded elongation was $1800 \%$ at a strain rate of $1.0 \times 10^{-1} \mathrm{~s}^{-1}$. The grain size in this material was $\approx 370 \mathrm{~nm}$ which is smaller than in the same alloy after processing by ECAP in part because HPT produces smaller grain sizes and in part because of the significantly lower processing temperature when using HPT.

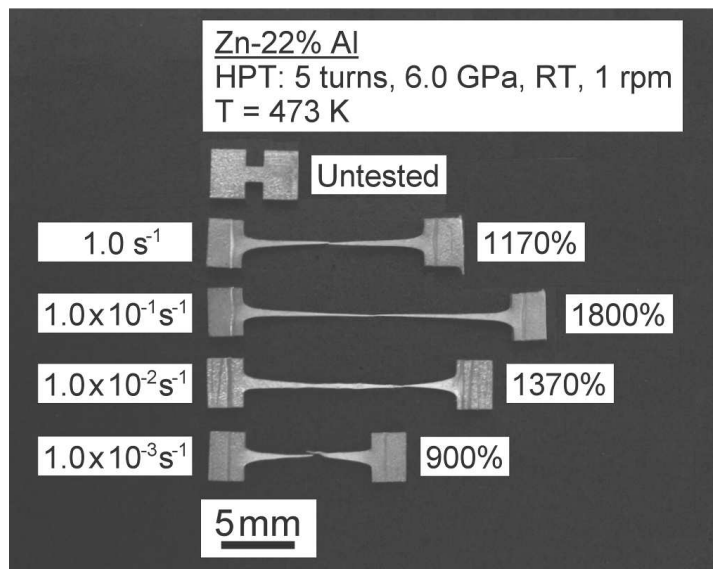

Fig. 6. The appearance of $\mathrm{Zn}-22 \% \mathrm{Al}$ specimens processed by HPT for 5 turns at room temperature and pulled to failure at different strain rates at $473 \mathrm{~K}$ [68].

It is possible to compare the elongations attained in this alloy after ECAP and HPT by plotting the results as the elongations to failure against the strain rate. The result is shown in Fig. 7 where the testing temperature is $473 \mathrm{~K}$ and results are shown, based on Figs. 5 and 6 , for the samples processed by ECAP [64] and HPT [68]. Since the grain size is smaller after processing by HPT, it is reasonable to anticipate that the maximum elongation will be displaced to a faster strain rate as shown correctly in Fig. 7. But generally a displacement to a faster strain rate will increase the maximum elongation whereas it is apparent from Fig. 7 that the maximum elongations for the HPT samples are reduced. This apparent discrepancy is discussed in detail in an earlier report [68] but it arises because of the very small cross-sectional areas in the tensile samples processed by HPT. It is now well established that the overall dimensions of tensile specimens influence the measured elongations to failure [71, 72] and the reduced elongations in the HPT specimens are a direct consequence of the reduced dimensions. 


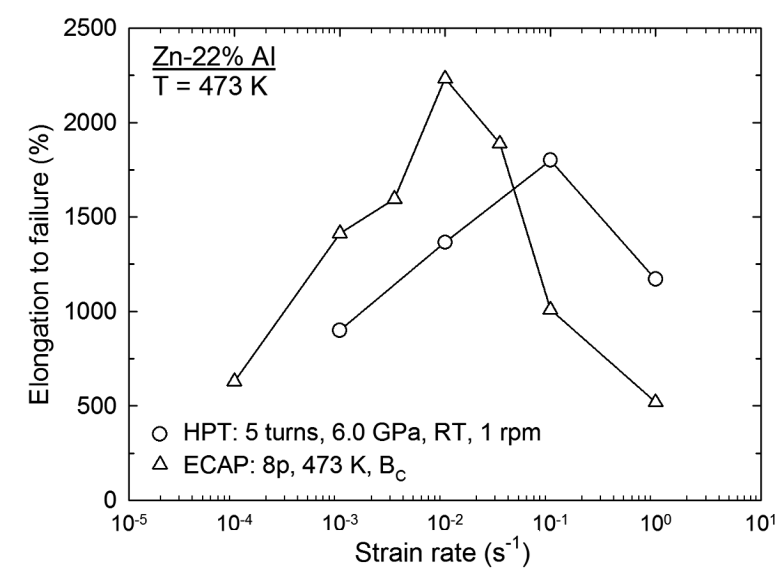

Fig. 7. A comparison of the measured elongations to failure in the $\mathrm{Zn}-22 \% \mathrm{Al}$ alloy at $473 \mathrm{~K}$ for specimens processed by ECAP [64] and by HPT [68].

\section{Introducing the concept of deformation mechanism maps}

In the high temperature creep of metals, deformation mechanism maps are a useful tool for displaying deformation mechanisms as a function of the fundamental parameters of high temperature flow including the applied stress, the testing temperature and the grain size. The principle of deformation mechanism maps was proposed over forty years ago in the form of a plot of the normalized stress, $\sigma / G$, against the homologous temperature, $T / T_{\mathrm{m}}$, for a constant grain size [73]. Specifically, a stress-temperature type of deformation mechanism map contains fields depicting the dominant creep mechanisms and strain rate contours are then added to provide additional information on the creep rates. This approach is now available for a large number of materials including metals, ceramics and geological materials [74].

In practice, it is difficult to construct these stresstemperature maps due to the necessity of extensive calculations in order to draw the curved field boundaries in stress-temperature space. Accordingly, alternative and simpler maps were suggested by plotting the normalized grain size, $d / \boldsymbol{b}$, against the normalized stress, $\sigma / G$, at constant temperature [75], plotting $d / \boldsymbol{b}$ against the inverse of the homologous temperature, $T_{\mathrm{m}} / T$, at constant stress [76] and plotting $\sigma / G$ against $T_{\mathrm{m}} / T$ at constant grain size [77] where all three types of maps give straight lines for both the field boundaries and the strain rate contours. These various types of deformation mechanism maps are widely used in high temperature creep for conventional coarse-grained metals but there have been very few attempts to date to use this same procedure for UFG materials produced through the application of SPD. Thus, the following sections present examples of maps for some representative metals processed by ECAP or HPT in the region of superplasticity and evaluates the general validity of these maps. A recent report summarized the use of deformation mechanism maps for depicting flow processes in superplastic UFG metals [78].

\section{Deformation mechanism maps for a $\mathrm{Pb}-\mathrm{Sn}$ alloy processed by ECAP}

The first attempt at constructing maps to evaluate high temperature flow after SPD processing was performed on $\mathrm{Pb}-62 \%$ Sn eutectic alloys processed by ECAP at room temperature through route $B_{\mathrm{C}}$ for 4,8 and 16 passes [79] and through route $\mathrm{A}$ for up to 5 passes [80] where route A denotes processing without rotation of the billet between each pass [69]. The former alloy was tested at $413 \mathrm{~K}$ and $10^{-3} \mathrm{~s}^{-1}$ and the latter alloy was tested at $423 \mathrm{~K}$ and $10^{-4}-10^{-1} \mathrm{~s}^{-1}$. Although the refined grain sizes were different in these alloys due to differences in the initial microstructures and the processing conditions, both alloys demonstrated excellent superplasticity where the former alloy achieved a maximum elongation of $\approx 3060 \%$ after 16 passes when testing at $413 \mathrm{~K} \mathrm{[79]}$ and the latter alloy achieved a maximum elongation of $2665 \%$ at $10^{-3} \mathrm{~s}^{-1}$ after 2 and 4 passes when testing at $423 \mathrm{~K}$ [80].

TABLE

Values of the parameters in Eq. (1) for construction of deformation mechanism maps for the $\mathrm{Pb}-62 \% \mathrm{Sn}$, $\mathrm{Zn}-22 \% \mathrm{Al}$ and $\mathrm{Al}-33 \% \mathrm{Cu}$ alloys.

\begin{tabular}{c|c|c|c|c}
\hline \hline Flow mechanism & $A$ & $D$ & $p$ & $n$ \\
\hline Nabarro-Herring [81, 82] & 28 & $D_{\ell}$ & 2 & 1 \\
\hline Coble [83] & 66.8 & $D_{\mathrm{gb}}$ & 3 & 1 \\
\hline Experimental: Pb- $=62 \% \mathrm{Sn}$ alloy [19,24] \\
\hline Region I & $1.5 \times 10^{14}$ & $D_{\ell}$ & 2.3 & 2.84 \\
Region II & $3.8 \times 10^{5}$ & $D_{\mathrm{gb}}$ & 2.3 & 1.85 \\
Region III & $4.2 \times 10^{9}$ & $D_{\ell}$ & 0 & 5 \\
\hline Experimental: $\mathrm{Zn}-22 \% \mathrm{Al}$ alloy $[23,85]$ \\
\hline Region I & $1.2 \times 10^{16}$ & $D_{\ell}$ & 2.4 & 3.77 \\
Region II & $1.6 \times 10^{5}$ & $D_{\mathrm{gb}}$ & 2.4 & 2.17 \\
Region III & $6.5 \times 10^{7}$ & $D_{\ell}$ & 0 & 5 \\
\hline Experimental: Al-33\% Cu alloy [86,87] \\
\hline Region I & $2 \times 10^{27}$ & $D_{\ell}$ & 2.1 & 5 \\
Region II & $5.2 \times 10^{3}$ & $D_{\mathrm{gb}}$ & 2.1 & 1.5 \\
Region III & $1.0 \times 10^{14}$ & $D_{\ell}$ & 0 & 5
\end{tabular}

Accordingly, deformation mechanism maps of $d / \boldsymbol{b}$ against $\sigma / G$ were constructed for both $\mathrm{Pb}-\mathrm{Sn}$ alloys at fixed testing temperatures and these are shown in Fig. 8 for (a) $413 \mathrm{~K}$ [79] and (b) $423 \mathrm{~K}$ [80]. For both maps, the experimental points are shown on the maps with information of the numbers of ECAP passes and grain sizes. The regions I, II and III denote the three regions of plastic flow associated with superplastic metals in the conventional sigmoidal plot [26] and the fields for NabarroHerring [81, 82] and Coble [83] diffusion creep are based on the theoretical predictions for these two mechanisms. Practically, the critical parameters for these three regions were taken from earlier experimental data for the same $\mathrm{Pb}-62 \% \mathrm{Sn}$ eutectic alloy $[19,24]$ and this gave activation energies of $84.2 \mathrm{~kJ} \mathrm{~mol}^{-1}$ and $57.8 \mathrm{~kJ} \mathrm{~mol}^{-1}$ for lattice and grain boundary diffusion, respectively [19], with $D_{0}=10^{-4} \mathrm{~m}^{2} \mathrm{~s}^{-1}, \boldsymbol{b}=3.2 \times 10^{-10} \mathrm{~m} \mathrm{[84]}$ and 
$G=2.2 \times 10^{4}-(1.61 \times 10 T)(\mathrm{MPa})[24]$. The relevant values of $A, D, p$ and $n$ for experimentally estimating regions I-III for the $\mathrm{Pb}-\mathrm{Sn}$ alloy and for the theoretical diffusion mechanisms are given in the Table where $D_{\ell}$ and $D_{\mathrm{gb}}$ are the coefficients for lattice and grain boundary diffusion, respectively. The dashed lines labeled $d / \boldsymbol{b}=20(\sigma / G)^{-1}$ correspond to the condition in Eq. (2) where the grain size is equal to the subgrain size. These dashed lines lie close to the boundaries between regions II and III thereby confirming that superplasticity requires a grain size smaller than the equilibrium subgrain size. Finally, it is apparent that the experimental points in both maps lie correctly within the superplastic region II.

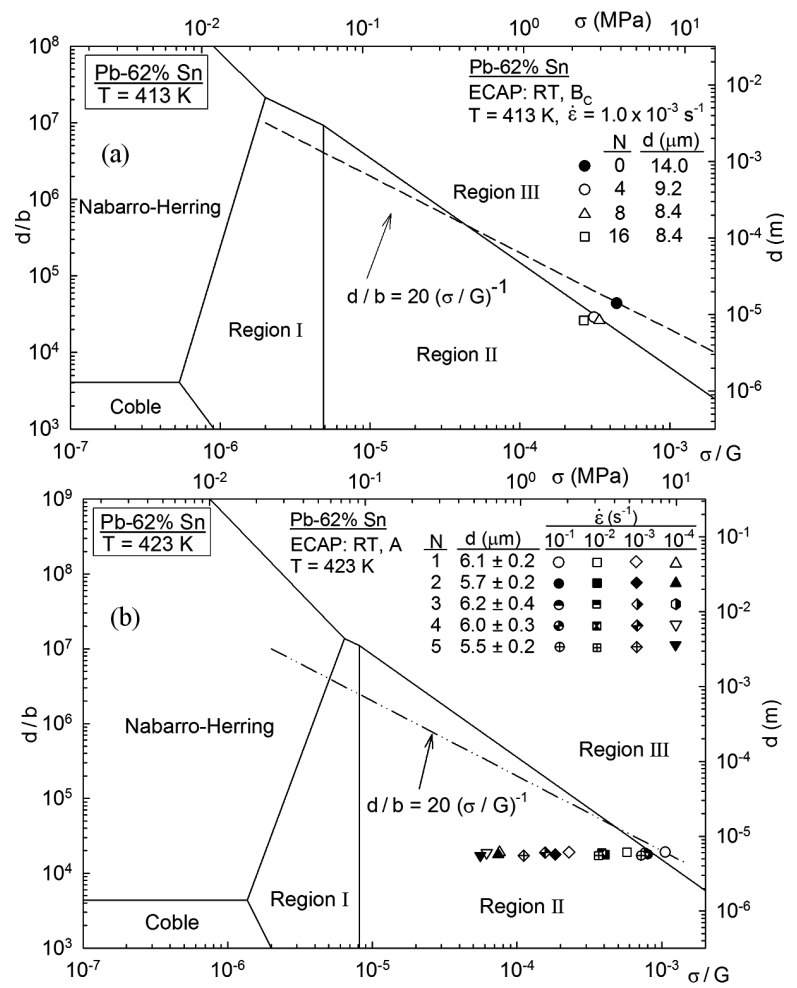

Fig. 8. Deformation mechanism maps of normalized grain size versus normalized stress for the $\mathrm{Pb}-62 \% \mathrm{Sn}$ alloy after ECAP under different conditions and testing at (a) $413 \mathrm{~K}$ [79] and (b) $423 \mathrm{~K}$ [80] showing the dominant flow mechanisms: the dashed line denotes the limiting condition for the formation of subgrains within the grains.

\section{A deformation mechanism map for a $\mathrm{Zn}-\mathrm{Al}$ alloy processed by ECAP and HPT}

Figure 9 presents a deformation mechanism map in the form of $d / \boldsymbol{b}$ against $\sigma / G$ for the $\mathrm{Zn}-22 \% \mathrm{Al}$ eutectoid alloy tested at $473 \mathrm{~K}$ : the map includes experimental points obtained after tensile testing of alloys processed by ECAP for 8 passes at $473 \mathrm{~K}$ [64] and by HPT for 5 turns at room temperature [68]. This map was plotted using the theoretical models for diffusion creep [81-83] and the fields for regions I-III are based on the parameters obtained experimentally in the
$\mathrm{Zn}-22 \% \mathrm{Al}$ alloy in an annealed condition without processing and after testing in tension at $473 \mathrm{~K}[23,85]$. The relevant values of $A, D, p$ and $n$ for the $\mathrm{Zn}-\mathrm{Al}$ alloy used in Eq. (1) are listed in the Table. Also, there are some other critical values used for constructing the map: $Q_{\ell} \approx 119 \mathrm{~kJ} \mathrm{~mol}^{-1}$ and $Q_{\mathrm{gb}} \approx 78.8 \mathrm{~kJ} \mathrm{~mol}^{-1}$ with $D_{0}=10^{-4} \mathrm{~m}^{2} \mathrm{~s}^{-1}[85], \boldsymbol{b}=2.7 \times 10^{-10} \mathrm{~m} \mathrm{[84]}$ and $G=4.797 \times 10^{4}-(2.662 \times 10 T)(\mathrm{MPa})[85]$.

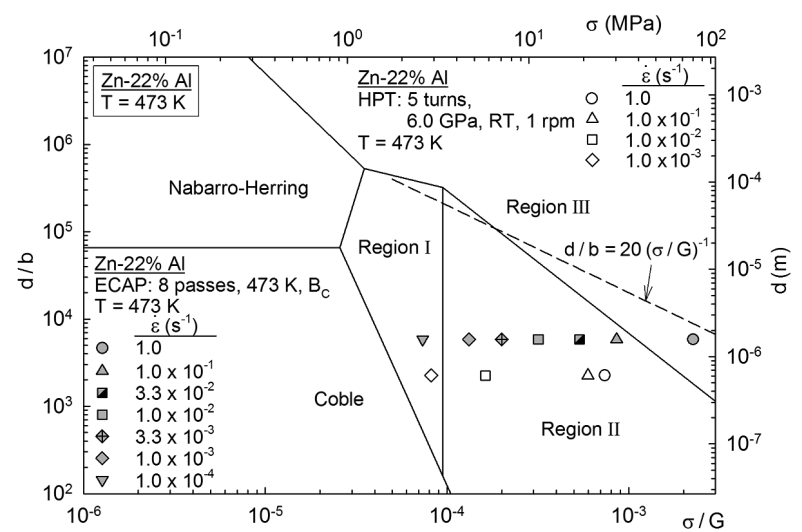

Fig. 9. A deformation mechanism map of normalized grain size versus normalized stress for a $\mathrm{Zn}-22 \% \mathrm{Al}$ eutectoid alloy tested at $473 \mathrm{~K}$ : the map includes the experimental points for the alloy processed by ECAP for 8 passes at $473 \mathrm{~K}[64]$ and by HPT for 5 turns at room temperature [68].

For ECAP samples, the microstructure was refined to have a spatial grain size of $d \approx 1.4 \mu \mathrm{m}$ so that the five datum points at the intermediate strain rates demonstrated optimum superplastic elongations of $>1000 \%$ including a highest elongation of $\approx 2230 \%$ at $1.0 \times 10^{-2} \mathrm{~s}^{-1}$ as shown in Fig. 5 [64]. Accordingly, these points fall within the field of the superplastic region II. Other samples gave lower ductilities at slower and faster strain rates and these points are in regions I and III, respectively. Processing by HPT refined the grains to $d \approx 600 \mu \mathrm{m}$ after 5 turns so that at $473 \mathrm{~K}$ the three specimens tested at the fastest strain rates lie within the superplastic region II. These optimum superplastic conditions gave excellent elongations of over $1000 \%$ including a highest elongation of $\approx 1800 \%$ at $1.0 \times 10^{-1} \mathrm{~s}^{-1}$ [68].

It should be noted that the grain sizes in the $\mathrm{Zn}-\mathrm{Al}$ alloys after SPD processing were too small to form subgrains so that all experimental points lie beneath the dashed line defining the equivalent subgrain sizes under these testing conditions. Thus, it is concluded that the deformation mechanism map based on the theoretical creep relationship given in Eq. (1) provides excellent agreement with the experimental results for both ECAP and HPT specimens.

\section{A deformation mechanism map \\ for an Al-Cu alloy processed by HPT}

The approach of constructing this same type of deformation mechanism map was also extended to an 
$\mathrm{Al}-33 \% \mathrm{Cu}$ alloy tested at $723 \mathrm{~K}$. The map is shown in Fig. 10 where the theoretical diffusion creep mechanisms and the fields of regions I-III were again considered in applying the parameters obtained theoretically and experimentally, respectively. The critical values for constructing the map for the $\mathrm{Al}-\mathrm{Cu}$ alloy are $Q_{\ell}=299 \mathrm{~kJ} \mathrm{~mol}^{-1}[86]$ and $Q_{\mathrm{gb}}=175 \mathrm{~kJ} \mathrm{~mol}^{-1}$ at $673-748 \mathrm{~K}$ [87] with $D_{0}=0.11 \mathrm{~m}^{2} \mathrm{~s}^{-1}$ [88], $\boldsymbol{b}=$ $2.86 \times 10^{-10} \mathrm{~m} \mathrm{[89]}$ and $G=3.8 \times 10^{4}-16.5 T(\mathrm{MPa})$ [87] and the adjusted values of $A, D, p$ and $n$ obtained from the experimental results of $\mathrm{Al}-33 \% \mathrm{Cu}$ alloys [86, 87] are listed in the Table.

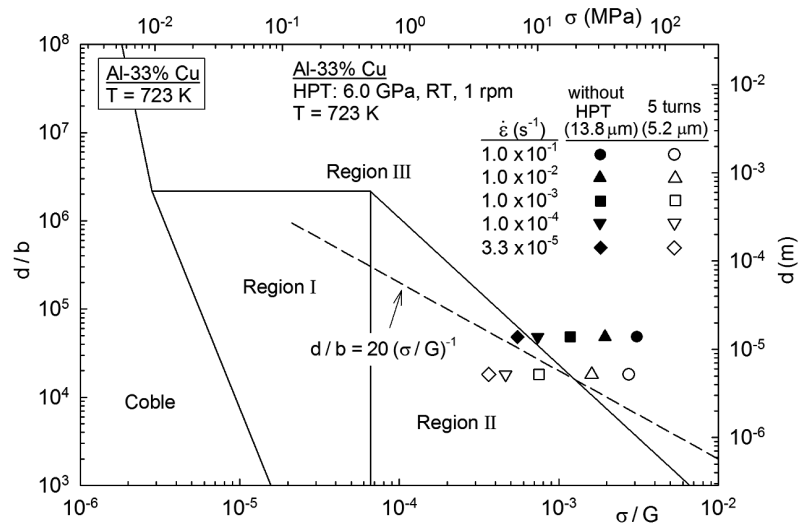

Fig. 10. A deformation mechanism map of normalized grain size versus normalized stress for an $\mathrm{Al}-33 \% \mathrm{Cu}$ eutectic alloy tested at $723 \mathrm{~K}$ : the map includes experimental points for the alloy processed by HPT for 5 turns at room temperature [56].

The $\mathrm{Al}-33 \% \mathrm{Cu}$ alloy was processed by HPT at room temperature through 5 turns so that the initial spatial grain size of $\approx 13.8 \mu \mathrm{m}$ was reduced to $\approx 5.2 \mu \mathrm{m}[56]$. Tensile testing was conducted at $723 \mathrm{~K}$ at five different strain rates between $3.3 \times 10^{-5}$ and $1.0 \times 10^{-1} \mathrm{~s}^{-1}$ and the processed samples demonstrated excellent superplastic elongations of over $\approx 700 \%$ at the three slowest strain rates whereas samples without HPT processing showed superplastic ductilities only at the two slowest strain rates [56]. The datum points corresponding to the superplastic behavior are reasonably within the superplastic region II so that these experimental results show excellent agreement with the deformation mechanism map constructed based on Eq. (1). Moreover, the dashed line labeled $d / \boldsymbol{b}=20(\sigma / G)^{-1}$ shows that the Al-33\% Cu alloy was refined to give a grain size which was below the limit of the equivalent subgrain size thereby permitting excellent superplastic flow under these testing conditions.

\section{Summary and conclusions}

1. Superplasticity is generally attained in metals with small grain sizes, typically $<10 \mu \mathrm{m}$, when testing in tension at temperatures above $\approx 0.5 T_{\mathrm{m}}$ where $T_{\mathrm{m}}$ is the absolute melting temperature.
2. Processing through the application of severe plastic deformation (SPD) produces ultrafine grain sizes which are typically in the submicrometer or the nanometer range and these materials provide a capability for producing excellent superplastic properties at exceptionally rapid strain rates. Examples are presented showing these superplastic elongations.

3. Deformation mechanism maps are a useful tool for predicting the rate-controlling flow process in tests conducted at elevated temperatures. A general agreement with the experimental data confirms the validity of constructing deformation mechanism maps for ultrafine-grained metals based on the predicted rate-controlling processes for coarse-grained materials.

\section{Acknowledgments}

This work was supported in part by the National Science Foundation of the United States under Grant No. DMR-1160966 and in part by the European Research Council under ERC Grant Agreement No. 267464SPDMETALS.

\section{References}

[1] C.E. Pearson, J. Inst. Metals 54, 111 (1934).

[2] Y. Ma, T.G. Langdon, Metall. Mater. Trans. 25A, 2309 (1994).

[3] A.J. Barnes, J. Mater. Eng. Perform. 16, 440 (2007).

[4] T.G. Langdon, Metall. Trans. 12A, 689 (1982).

[5] T.G. Langdon, Metall. Mater. Trans. 33A, 249 (2002).

[6] T.G. Langdon, Z. Metallk. 96, 522 (2005).

[7] D.A. Woodford, Trans. ASM 62, 291 (1969).

[8] T.G. Langdon, Scr. Metall. 11, 997 (1977).

[9] F.A. Mohamed, Scr. Metall. 12, 99 (1978).

[10] T.G. Langdon, Mater. Sci. Eng. A 174, 225 (1994).

[11] J.W. Edington, K.N. Melton, C.P. Cutler, Prog. Mater. Sci. 21, 61 (1976).

[12] R.Z. Valiev, O.A. Kaibyshev, Acta Metall. 31, 2121 (1983).

[13] L.K.L. Falk, P.R. Howell, G.L. Dunlop, T.G. Langdon, Acta Metall. 34, 1203 (1986).

[14] R.Z. Valiev, T.G. Langdon, Acta Metall. Mater. 41, 949 (1993).

[15] Y. Xun, F.A. Mohamed, Philos. Mag. 83, 2247 (2003).

[16] T.G. Langdon, J. Mater. Sci. 44, 5998 (2009).

[17] J.E. Bird, A.K. Mukherjee, J.E. Dorn, in: Quantitative Relation Between Properties and Microstructure, Eds. D.G. Brandon, A. Rosen, Israel Universities Press, Jerusalem 1969, p. 255.

[18] W.R. Cannon, T.G. Langdon, J. Mater. Sci. 23, 1 (1988).

[19] F.A. Mohamed, T.G. Langdon, Scr. Metall. 10, 759 (1976). 
[20] T.G. Langdon, Acta Metall. Mater. 42, 2437 (1994).

[21] M.L. Vaidya, K.L. Murty, J.E. Dorn, Acta Metall. 21, 1615 (1973).

[22] A. Arieli, A.K.S. Yu, A.K. Mukherjee, Metall Trans. 11A, 181 (1980).

[23] F.A. Mohamed, T.G. Langdon, Acta Metall. 23, 117 (1975).

[24] F.A. Mohamed, T.G. Langdon, Philos. Mag. 32, 697 (1975).

[25] G. Rai, N.J. Grant, Metall. Trans. 6A, 385 (1975).

[26] H. Ishikawa, F.A. Mohamed, T.G. Langdon, Philos. Mag. 32, 1269 (1975).

[27] P.K. Chaudhury, F.A. Mohamed, Acta Metall. 36, 1099 (1988).

[28] P.K. Chaudhury, V. Sivaramakrishnan, F.A. Mohamed, Metall. Trans. 19A, 2741 (1988).

[29] S. Yan, J.C. Earthman, F.A. Mohamed, Philos. Mag. 69, 1017 (1994).

[30] T.G. Langdon, Acta Mater. 61, 7035 (2013).

[31] R.Z. Valiev, T.G. Langdon, Prog. Mater. Sci. 51, 881 (2006).

[32] A.P. Zhilyaev, T.G. Langdon, Prog. Mater. Sci. 53, 893 (2008).

[33] A.P. Zhilyaev, B.K. Kim, G.V. Nurislamova, M.D. Baró, J.A. Szpunar, T.G. Langdon, Scr. Mater. 46, $575(2002)$

[34] A.P. Zhilyaev, G.V. Nurislamova, B.K. Kim, M.D. Baró, J.A. Szpunar, T.G. Langdon, Acta Mater. 51, 753 (2003).

[35] J. Wongsa-Ngam, M. Kawasaki, T.G. Langdon, J. Mater. Sci. 48, 4653 (2013).

[36] R.Z. Valiev, O.A. Kaibyshev, R.I. Kuznetsov, R.Sh. Musalimov, N.K. Tsenev, Doklady Akad. Nauk SSSR 301, 864 (1988).

[37] Y. Ma, M. Furukawa, Z. Horita, M. Nemoto, R.Z. Valiev, T.G. Langdon, Mater. Trans. JIM 37, 336 (1996).

[38] K. Higashi, M. Mabuchi, T.G. Langdon, ISIJ Int. 36, 1423 (1996).

[39] R.Z. Valiev, D.A. Salimonenko, N.K. Tsenev, P.B. Berbon, T.G. Langdon, Scr. Mater. 37, 1945 (1997).

[40] T.G. Langdon, Metal Sci. 16, 175 (1982).

[41] M. Kawasaki, T.G. Langdon, J. Mater. Sci. 42 , 1782 (2007)

[42] M. Kawasaki, T.G. Langdon, J. Mater. Sci. 49 , 6487 (2014).

[43] M. Kawasaki, N. Balasubramanian, T.G. Langdon, Mater. Sci. Eng. A 528, 6624 (2011).

[44] R.K. Islamgaliev, N.F. Yunusova, R.Z. Valiev, N.K. Tsenev, V.N. Perevezentsev, T.G. Langdon, Scr. Mater. 49, 467 (2003).

[45] F. Musin, R. Kaibyshev, Y. Motohashi, G. Itoh, Metall. Mater. Trans. 35A, 2383 (2004).

[46] K.T. Park, D.Y. Hwang, Y.K. Lee, D.H. Shin, Mater. Sci. Eng. A 341, 273 (2003).

[47] I. Nikulin, R. Kaibyshev, T. Sakai, Mater. Sci. Eng. A 407, 62 (2005).
[48] S. Komura, M. Furukawa, Z. Horita, M. Nemoto, T.G. Langdon, Mater. Sci. Eng. A 297, 111 (2001).

[49] S. Komura, Z. Horita, M. Furukawa, M. Nemoto, T.G. Langdon, Metall. Mater. Trans. 32A, 707 (2001).

[50] S. Lee, A. Utsunomiya, H. Akamatsu, K. Neishi, M. Furukawa, Z. Horita, T.G. Langdon, Acta Mater. 50, 553 (2002).

[51] R.S. Mishra, R.Z. Valiev, S.X. McFadden, R.K. Islamgaliev, A.K. Mukherjee, Philos. Mag. A 81, 37 (2001).

[52] V.N. Perevezentsev, M.Yu. Shcherban, M.Yu. Murashkin, R.Z. Valiev, Tech. Phys. Lett. 33, 648 (2007).

[53] S.V. Dobatkin, E.N. Bastarache, G. Sakai, T. Fujita, Z. Horita, T.G. Langdon, Mater. Sci. Eng. A 408 141 (2005).

[54] C. Xu, S.V. Dobatkin, Z. Horita, T.G. Langdon, Mater. Sci. Eng. A 500, 170 (2009).

[55] S. Sabbaghianrad, M. Kawasaki, T.G. Langdon, J. Mater. Sci. 47, 7789 (2012).

[56] M. Kawasaki, J. Foissey, T.G. Langdon, Mater. Sci. Eng. A 561, 118 (2013).

[57] G. Sakai, Z. Horita, T.G. Langdon, Mater. Sci. Eng. A 393, 344 (2005).

[58] Y. Harai, K. Edalati, Z. Horita, T.G. Langdon, Acta Mater. 57, 1147 (2009).

[59] F.A. Mohamed, M.M.I. Ahmed, T.G. Langdon, Metall. Trans. 8A, 933 (1977).

[60] M.M.I. Ahmed, F.A. Mohamed, T.G. Langdon, J. Mater. Sci. 14, 2913 (1979).

[61] F.A. Mohamed, T.G. Langdon, Acta Metall. 29, 911 (1981).

[62] P. Shariat, R.B. Vastava, T.G. Langdon, Acta Metall. 30, 285 (1982).

[63] Z.R. Lin, A.H. Chokshi, T.G. Langdon, J. Mater. Sci. 23, 2712 (1988).

[64] M. Kawasaki, T.G. Langdon, Mater. Trans. 49, 84 (2008).

[65] M. Kawasaki, T.G. Langdon, Mater. Sci. Eng. A 503, 48 (2009).

[66] M. Kawasaki, T.G. Langdon, Mater. Trans. 53, 87 (2012).

[67] M. Kawasaki, T.G. Langdon, J. Mater. Sci. 48 4730 (2013)

[68] M. Kawasaki, T.G. Langdon, Mater. Sci. Eng. A 528, 6140 (2011)

[69] M. Furukawa, Y. Iwahashi, Z. Horita, M. Nemoto, T.G. Langdon, Mater. Sci. Eng. A 257, 328 (1998).

[70] Y. Iwahashi, J. Wang, Z. Horita, M. Nemoto, T.G. Langdon, Scr. Mater. 35, 143 (1996).

[71] Y.H. Zhao, Y.Z. Guo, Q. Wei, A.M. Dangelewicz, C. Xu, Y.T. Zhu, T.G. Langdon, Y.Z. Zhou, E.J. Lavernia, Scr. Mater. 59, 627 (2008).

[72] Y.H. Zhao, Y.Z. Guo, Q. Wei, T.D. Topping, A.M. Dangelewicz, Y.T. Zhu, T.G. Langdon, E.J. Lavernia, Mater. Sci. Eng. A 525, 68 (2009).

[73] M.F. Ashby, Acta Metall. 20, 887 (1972). 
[74] H.J. Frost, M.F. Ashby, Deformation-Mechanism Maps: The Plasticity and Creep of Metals and Ceramics, Pergamon Press, Oxford 1982.

[75] F.A. Mohamed, T.G. Langdon, Metall. Trans. 5, 2339 (1974).

[76] T.G. Langdon, F.A. Mohamed, Mater. Sci. Eng. A 32, 103 (1978)

[77] T.G. Langdon, F.A. Mohamed, J. Mater. Sci. 13, 1282 (1978)

[78] M. Kawasaki, T.G. Langdon, J. Mater. Sci. 47, 7726 (2012)

[79] M. Kawasaki, S. Lee, T.G. Langdon, Scr. Mater. 61, 963 (2009)

[80] M. Kawasaki, A. de Mendes, V.L. Sordi, M. Ferrante, T.G. Langdon, J. Mater. Sci. 46, 155 (2011).

[81] F.R.N. Nabarro, in: Report of a Conference on Strength of Solids, The Physical Society, London 1948, p. 75 .
[82] C. Herring, J. Appl. Phys. 21, 437 (1950).

[83] R.L. Coble, J. Appl. Phys. 34, 1679 (1963).

[84] T.G. Langdon, F.A. Mohamed, Scr. Metall. 11, 575 (1977).

[85] F.A. Mohamed, S.-A. Shei, T.G. Langdon, Acta Metall. 23, 1443 (1975).

[86] A.H. Chokshi, T.G. Langdon, Metall. Trans. A 19A, 2487 (1988).

[87] A.H. Chokshi, T.G. Langdon, Scr. Metall. 21, 1669 (1987).

[88] E. Ho, G.C. Weatherly, Acta Metall. 23, 1451 (1975).

[89] A.H. Chokshi, T.G. Langdon, J. Mater. Sci. 24, 143 (1989). 